\title{
Overcoming Barriers to Contraceptive Uptake among Adolescents: The Case of Kiambu County, Kenya
}

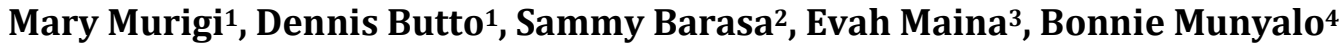 \\ ${ }^{1}$ School of Health Sciences, Kirinyaga University College, Kerugoya, Kenya \\ ${ }^{2}$ Kenya Medical Training College, Chuka Campus, Chuka, Kenya \\ ${ }^{3}$ Department of Medical Services, Kirinyaga University College, Kerugoya, Kenya \\ ${ }^{4}$ AMFREF Health Africa, Nairobi, Kenya \\ Email: mmurigi@kyuc.ac.ke
}

How to cite this paper: Murigi, M., Butto, D., Barasa, S., Maina, E. and Munyalo, B. (2016) Overcoming Barriers to Contraceptive Uptake among Adolescents: The Case of Kiambu County, Kenya. Journal of Biosciences and Medicines, 4, 1-10. http://dx.doi.org/10.4236/jbm.2016.49001

Received: July 19, 2016

Accepted: September 3, 2016

Published: September 6, 2016

Copyright $\odot 2016$ by authors and Scientific Research Publishing Inc. This work is licensed under the Creative Commons Attribution International License (CC BY 4.0).

http://creativecommons.org/licenses/by/4.0/ (c) (i) Open Access

\begin{abstract}
Despite high sexual activity among adolescent girls in Kenya, contraceptive uptake is very low with only about 26 percent sexually active adolescent girls currently using a contraceptive method. This exposes them to HIV infections and unplanned pregnancies which consequently lead to school dropouts, unsafe abortions, and lack of employment opportunities. This cross-sectional study aimed at assessing the utilization of contraceptives among secondary school adolescent girls in Karuri Town Council, Kiambu County. Overall, 421 girls aged between 13.0 to 19.0 years took part in the study. Findings showed that despite majority (77.5\%) of the adolescent girls having had sexual debut by the age of 15 years, contraceptive utilization was very low at $43 \%$. The results revealed that age of the adolescent, knowledge of contraceptives options, perception and accessibility of the contraceptives had positive significant effect on contraceptive utilization. Adolescents aged 18 years and above were more likely to utilize contraceptives as compared to those of a lesser age ( $\mathrm{p} \leq 0.001$; OR: 9.870 (95\% CI: 3.781 - 25.763)). Those with knowledge on contraceptives were OR 3.2 times more likely to use contraceptives $(\mathrm{p}=0.025)$, similarly, accessibility was significantly associated with increased contraceptive utilization ( $\mathrm{p}=0.34,95 \% \mathrm{CI}$ : 1.054 - 4.187). Adolescents who perceived use of contraceptives as wise were more likely to use a contraceptive than those of a divergent opinion (OR: 2.053 (95\% CI: 1.024 - 4.115), $\mathrm{p}=0.041$ ). This revealed that high level of knowledge on contraceptives did not always amount to practice. There is therefore a need to develop age specific reproductive health messages to guide school education curriculum as well as parent or guardian-child communication.
\end{abstract}




\section{Keywords}

Adolescents, Contraceptive Prevalence Rate, Sexual Debut

\section{Introduction}

The World Health Organization (WHO) defines an adolescent as a person aged $10-19$ years [1]. Adolescence is a time of increased physical and mental changes that affect their sexuality \& sexual preferences. Adolescents therefore face psychological challenges associated with possible sexual relationships with the opposite sex (Imaledo, Peter-Kio, \& Asuquo, 2012). As a result, adolescents can become parents without being ready for parental responsibility [2].

There are about 1.2 billion adolescents worldwide making a fifth of the world's population. Eighty percent of these adolescents live in developing countries [3]. In Kenya, according to Kenya Population Situation Analysis 2013, one in every five Kenyans is an adolescent therefore making a significant percentage of the population.

Adolescent fertility regulation and pregnancy prevention are one of the most important health care issues of the twenty-first century. This is because worldwide, more than 16 million adolescent girls give birth every year, and an additional 5 million have abortions [4]. Sub-Saharan Africa accounts for 50\% of these births. In sub-Saharan Africa, and Asia, more than $60 \%$ of adolescents who wish to avoid pregnancy have an unmet need for modern contraception. The adolescents who do not use modern contraception or rely instead on a traditional method of family planning account for more than $80 \%$ of unintended pregnancies among adolescents [5]. Hence the need for specially tailored adolescent's sexual and reproductive health services has become more pressing.

Adolescents have their first sexual experience at an early age [6]. Globally, studies on adolescent sexual behaviour show their premarital sexual encounters are generally unplanned, infrequent and sporadic [7]. While this is the case, they face a high unmet need for contraception predisposing them to unplanned pregnancies and risk of unsafe abortion [8]. Unplanned adolescent pregnancy is associated with unsafe abortion, a cause of $13 \%$ of global maternal mortality [9]. It's more dangerous for adolescents as they tend to seek abortion later in pregnancy. By meeting the contraceptive needs of these adolescents, this problem could be prevented.

Industrialization and urbanization has eroded family ties and traditional values that inhibited premarital sexual activity [10]. Adolescents therefore are no longer always able to rely on intergenerational relationships, which in the past might have given them information about responsible sexual behaviour. Parents on the other hand are uncomfortable discussing sexuality and contraception with their children, a task that has been left to schools already limited by the current debates on sex education [7]. As the generational gap widens, adolescents are forced to learn about sexual issues from their peers or the mass media [11]. 
Unlike popular believe, educating adolescents on contraception does not promote promiscuity [6]. Although some adults may find the idea disturbing, the reality now is that many adolescents have sexual relations before they are ready for marriage and families [12]. This gap between adult attitudes and adolescent realities is a recipe for early pregnancy. Compounding this is the low level of contraceptive use amongst adolescents [9].

The evidence is consistent with what is observed in Kenya where one in five adolescents has ever been pregnant [13]. The Kenya Demographic Health Survey report of the year 2008/09 showed most adolescents now aged 15 - 19 years had had sex before they were 15 years old; some become sexually active before the age of 12 years [13]. Even though many adolescents wish to avoid pregnancy in Kenya, they are not using contraceptives to make this possible [13]. As a result, nearly half (47\%) of births to these adolescents are unplanned and consequently, the age-specific fertility rate among adolescents in Kenya is 103 per 1000 women [14].

Adolescent pregnancy in Kenya is one of the leading causes of school dropout with up to 13,000 adolescent girls dropping out of school every year as a result of unplanned pregnancy [15]. In addition, adolescent's unplanned pregnancies result in unsafe abortion leading to Maternal Mortality. These mortalities add to the Maternal Mortality Rate (MMR) which is currently estimated at 488 deaths per 100,000 live births in Kenya [14]. The question therefore becomes why the adolescents are not using the contraceptives to prevent unplanned pregnancies.

Investing in contraception is more cost effective than managing unplanned adolescent pregnancy and caring for more children [16]. A report from the World Bank indicated that if 1.6 million adolescent girls in Kenya, completed secondary school, and were employed instead of having become pregnant, the cumulative effect could have added $\$ 3.4$ billion to Kenya's gross income every year. This is equivalent to the entire Kenyan construction sector [17].

With the exception of tubal ligation and vasectomy, all methods that are physiologically safe for adults are also physiologically safe for adolescents [18]. The prevention of unplanned adolescent pregnancies requires: a desire to use contraceptives, a good contraceptive method, ability to obtain the contraceptive method, and ability to use it. If one of this is missing contraception will fail [19].

Contraceptive utilization remains low in the Kenyan context, while this is the case, little is known on the factors that underlie the low contraceptive uptake among this sub population. Most studies in Kenya have focused on adolescent's sexual activity and sexually transmitted infections. Very little however has been done on adolescent contraception. The purpose of this study therefore was to identify the barriers to contraceptive uptake and suggest their mitigating strategies among secondary school adolescent girls in Karuri Town Council, Kiambu County, Kenya.

\section{Material and Methods}

A cross sectional study design using quantitative and qualitative methods of data col- 
lection was conducted in the selected secondary schools in Karuri Town Council, Kiambu County. Quantitative data was collected using semi structured questionnaires while qualitative data was collected using purposively selected Focused Group Discussions (FGDs). The researcher conducted a total of 5 FGDs each with a minimum of 6 and a maximum of 8 participants. The study participants were 421 secondary school adolescent girls proportionately sampled from different secondary schools in Karuri Town Council, Kiambu County.

Only adolescent girls from the selected schools in Karuri Town Council, Kiambu County; who gave a written informed consent to participate in the study are included. Statistical analysis for quantitative data was performed using IBM Statistical Package for Social Sciences (SPSS) 21.0 while qualitative data was analyzed using thematic content analysis. Frequency distributions showed the distribution of the study population by background characteristics while Chi-square and fishers exact test values were used to test the significance of the association between the dependent and independent variables. The thresh hold for statistical significance was set at $\mathrm{P}<0.05$.

\section{Results and Discussion}

\subsection{Characteristics of the Participants}

Table 1 represents the socio-demographic characteristics of the adolescent girls who participated in the study. A total of 421 adolescents selected from nine public secondary schools from Karuri Town Council took part in the study. Most of the study participants were from rural areas (59.1\%) with the rest resided either in a peri-urban area (27.1\%) or an urban area (13.8\%). Majority of the respondents were Christians (91.4\%). Proportionately, the students selected from Form 1 were (25.7\%), form 2 (26.1\%), form 3 (24.7\%) and form 4 (23.5\%). The participants' age ranged from 13.0 to 19.0 years with a mean age of 16.3 years.

\subsection{Sexual Activity}

Figure 1 shows the age of the participants at sexual debut. 142 students (33.7\%) had ever engaged in sexual intercourse. The mean age of sexual debut was 15.0 years. The proportion of students initiated into sex increased with age peaking at 15 years (45.8\%). Being in a mixed secondary school was associated with increased likelihood of having had sex as compared to being in a girls-only school ( $\mathrm{p}=0.038$; $\mathrm{OR}=1.586 ; 95 \% \mathrm{CI}$ : $1.024-2.458)$.

\subsection{Knowledge on Contraceptives}

Figure 1 shows the types of modern contraceptives identified by the respondents. There was a $90.1 \%$ level of knowledge on contraceptives. The main source of information on contraceptives was electronic and print media (59.3\%) followed by peers (40.4\%). Teachers, health care workers and parents accounted for the least as sources of information at $(7.2 \%, 5.1 \%$ and $4.8 \%)$ respectively. The high (90.1\%) level of knowledge on contraceptives tallies with the findings of a research in Kisumu Kenya that showed 
Table 1. Socio demographic characteristics of the respondents.

\begin{tabular}{|c|c|c|}
\hline Characteristic & Frequency & $\%$ \\
\hline \multicolumn{3}{|c|}{ Age category (years) } \\
\hline$<15$ & 40 & 9.5 \\
\hline $15-17$ & 286 & 67.9 \\
\hline$\geq 18$ & 95 & 22.6 \\
\hline \multicolumn{3}{|l|}{ Residence } \\
\hline Rural & 249 & 59.1 \\
\hline Urban & 114 & 27.1 \\
\hline Peri-urban & 58 & 13.8 \\
\hline \multicolumn{3}{|c|}{ Lives with family members } \\
\hline Yes & 380 & 90.3 \\
\hline No & 41 & 9.7 \\
\hline \multicolumn{3}{|l|}{ Religion } \\
\hline Christian & 385 & 91.4 \\
\hline Muslim & 36 & 8.6 \\
\hline \multicolumn{3}{|l|}{ Level of Education } \\
\hline Form 1 & 108 & 25.7 \\
\hline Form 2 & 110 & 26.1 \\
\hline Form 3 & 104 & 24.7 \\
\hline Form 4 & 99 & 23.5 \\
\hline \multicolumn{3}{|c|}{ Ever engaged in sexual intercourse } \\
\hline Yes & 142 & 33.7 \\
\hline No & 279 & 66.3 \\
\hline \multicolumn{3}{|c|}{ Age of sex debut $(n=142)$} \\
\hline$\leq 14$ & 45 & 31.7 \\
\hline 15 & 65 & 45.8 \\
\hline 16 & 19 & 13.4 \\
\hline$\geq 17$ & 13 & 9.1 \\
\hline
\end{tabular}




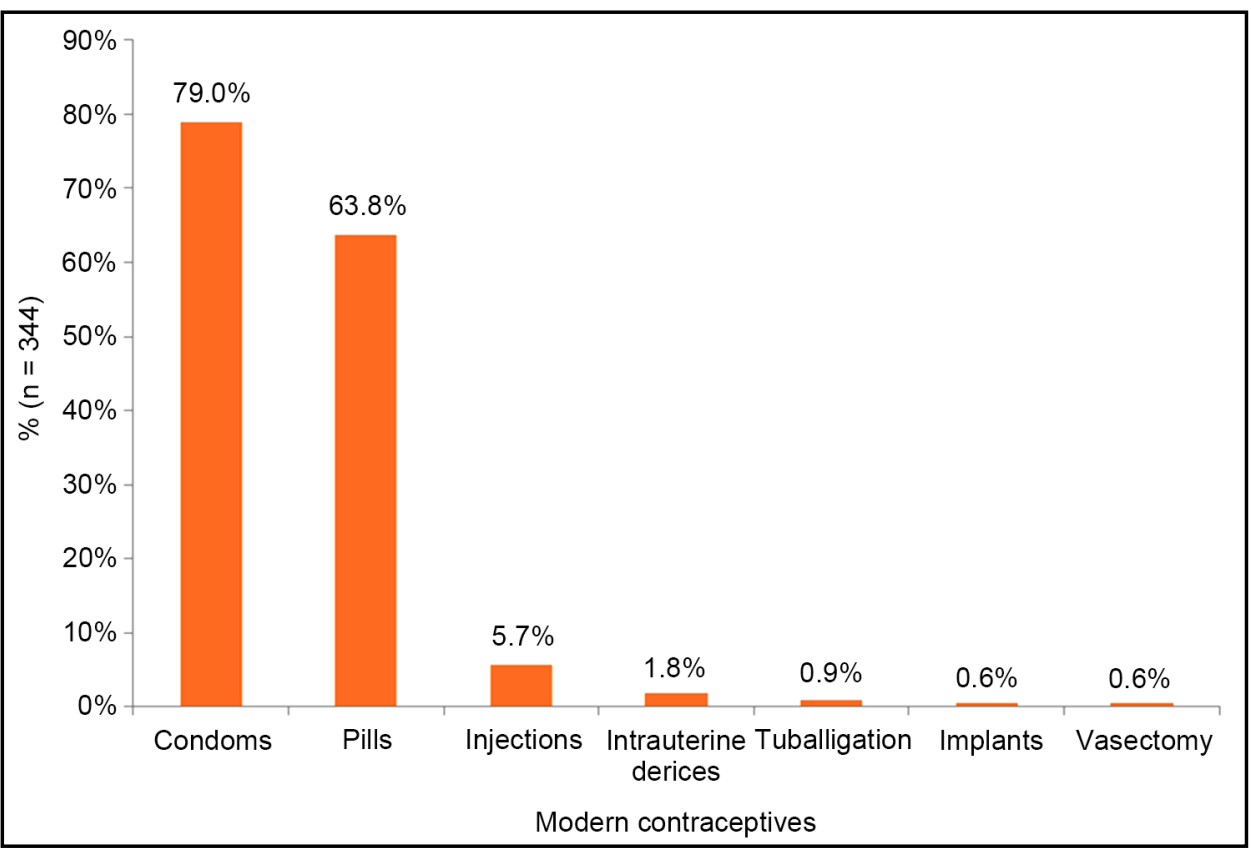

Figure 1. Types of modern contraceptives mentioned by the respondents.

99.2\% level of knowledge of at least one contraceptive method [7]. The KDHS 2009/08 also reported $95 \%$ knowledge of at least one modern contraceptive method.

\subsection{Level of Contraceptive Utilization}

Table 2 represents contraceptive utilization among the participants. Of the 142 respondents who were sexually active $43.0 \%$ reported having ever used a modern method of contraception. Majority utilized the pill (83.6\%). Despite initiating sexual activity at an early age, contraceptive uptake among the secondary school adolescent girls was low. The findings of this study are however higher in comparison to those of KDHS 2008/09 that showed among unmarried sexually active adolescents 15 - 19 years the CPR for any modern method was $23 \%$ [14].

\subsection{Factors Influencing Utilization of Contraceptives}

Table 3 illustrates factors influencing contraceptive utilization.

Age: Uptake of contraceptives increased in tandem with age. Adolescent girls who were 18 years of age were 10 times more likely to utilize contraceptives as compared to their counterparts of lesser age ( $\mathrm{p} \leq 0.001$; OR: 9.870 (95\% CI: 3.781 - 25.763)). Tripp in his study in the United Kingdom concluded that sex at an early age is compounded by lack of knowledge, lack of access to contraception, lack of skills and self-efficacy to negotiate contraception, or inadequate self-efficacy to resist pressure [20].

Knowledge on contraceptives: This study identified that among the sexually active adolescents, having knowledge on contraceptives increases by three times the likelihood to use contraceptives (OR: 3.200, 95\% CI: 1.115 - 9.183, $\mathrm{p}=0.025$ ). Having knowledge on contraception increases an adolescent's likelihood to use a contraceptive method as 
Table 2. Contraceptive utilization.

\begin{tabular}{ccc}
\hline Characteristic & Frequency & $\%$ \\
\hline Did you use any contraceptives? $(\mathbf{n}=\mathbf{1 4 2})$ & 61 & 43.0 \\
Yes & 81 & 57.0 \\
No & & \\
Which contraceptive $(\mathbf{s})$ have you ever used? $(\mathbf{n}=61)$ & 51 & 83.6 \\
Pills & 35 & 57.4 \\
Condoms & 10 & 16.4 \\
Injection & & \\
\hline
\end{tabular}

Table 3. Factors influencing contraceptive utilization.

\begin{tabular}{ccccccc}
\hline \multirow{2}{*}{ Attributes } & \multirow{2}{*}{ Total } & \multicolumn{2}{l}{ Contraceptive utilization } & & OR & p-value \\
Age (yrs) & & & Yes & No & & \\
\cline { 1 - 1 }$\geq 18$ & 62 & $22(35.5 \%)$ & $40(64.5 \%)$ & 9.870 & $<0.001$ \\
17 & 35 & $21(60.0 \%)$ & $14(40.0 \%)$ & 3.619 & 0.014 \\
$\leq 16$ & 45 & $38(84.4 \%)$ & $7(15.6 \%)$ & &
\end{tabular}

Age at sexual debut

$\begin{array}{llllll}\leq 15 & 110 & 67(60.9 \%) & 43(39.1 \%) & 0.499 & 0.084 \\ \geq 16 & 32 & 14(43.8 \%) & 18(56.3 \%) & & \end{array}$

Knowledge on contraceptives

$\begin{array}{llllll}\text { Yes } & 119 & 63(52.9 \%) & 56(47.1 \%) & 3.200 & 0.025 \\ \text { No } & 23 & 18(78.3 \%) & 5(21.7 \%) & & \end{array}$

Accessibility

$\begin{array}{llllll}\text { Yes } & 81 & 40(49.4 \%) & 41(50.6 \%) & 2.101 & 0.034 \\ \text { No } & 61 & 41(67.2 \%) & 20(32.8 \%) & & \end{array}$

Perception (wise to use contraceptives)

Yes
No
rian approval of
raceptive use

$84 \quad 42(50.0 \%) \quad 42(50.0 \%) \quad 2.053 \quad 0.041$

Parent/guardian approval of contraceptive use

$\begin{array}{llllll}\text { Yes } & 24 & 12(50.0 \%) & 12(50.0 \%) & 1.408 & 0.445 \\ \text { No } & 118 & 69(58.5 \%) & 49(41.5 \%) & & \end{array}$

Religion

Christian

127

$73(57.5 \%)$

$54(42.5 \%)$

0.845

0.759

Muslim

15

$8(53.3 \%) \quad 7(46.7 \%)$ 
compared to having no knowledge at all (MOH, 2007). Similarly, having knowledge exposes one to more interactions and other sources of information that enables one to make wise decisions such as using a contraceptive when sexually active [7].

Accessibility: Having accessibility to contraceptives was significantly associated with increased uptake of contraceptives ( $\mathrm{p}=0.034$; OR: 2.101; (95\% CI: $1.054-4.187)$ ). This was further qualified by the qualitative data where the participants reported... "We (adolescents) feel shy to go purchase contraceptives and most times the hospitals don't have contraceptives and if they do there is clinic and contraceptive fee and most of us have to ask our parents for the money not to mention long queues and long waiting hours. "The findings of this study tally with those of a study on sexual and reproductive health provision to young people in Kenya that found the reproductive services mostly inadequate and inaccessible to the adolescents either due to unavailability, un-affordability and the poor attitude from the health care givers [21]. A research among Sub Saharan countries by Moore showed that adolescents are dependent on their parents for economic support contributing to the non-utilization of contraceptives clinic fees and the contraceptive fees hinder adolescent's utilization of contraceptives [22].

Perception: perception was significantly associated with contraceptive utilization ( $\mathrm{p}$ $=0.041$; OR: 2.053; (95\% CI: $1.024-4.115)$ ). If adolescents do not think they are at risk of pregnancy or have the attitude "it won't happen to me", then they are less likely to make any decision at all regarding contraception.

Age at sexual debut, parental support, peer influence and religion were not significantly associated with contraceptive utilization.

\section{Conclusion}

Contraceptives help women plan when and how many children to have. Without contraceptives, women of any age will be unable to realize their own desire to avoid a pregnancy. It is concluded from this study that while adolescents are engaging in sexual activities at a young age and despite a high level of knowledge, the level of contraceptive utilization among secondary school adolescent girls is low. The factors influencing contraceptive utilization are age, accessibility, perception on contraception and knowledge on contraceptives. The prevention of unplanned adolescent pregnancies requires: a desire to use contraceptives, a good contraceptive method, ability to obtain the contraceptive method, and ability to use it. These can only be achieved when adolescents delay sexual debut, and have good positive perceptions and good knowledge on contraceptives.

\section{Recommendations}

Policy planning and implementation of adolescent's Sexual and Reproductive Health (SRH) issues should be a priority. Combined efforts should be made to increases the accessibility, availability and the affordability of contraceptives to adolescents. The ministry of health should therefore subsidize contraceptives, which will likely increase adolescents SRH seeking behaviour. Adolescent's risky sexual behaviour predispos- 
es them to STIs and unplanned pregnancies hence promotion and provision of dual protection methods that is condoms is of great importance.

The health system should offer adolescent-friendly services that are confidential, accessible and acceptable to adolescents. This way, they will not shy away from seeking services such as contraception. To enhance contraceptive use among adolescents and to improve on sexuality education between parents and the adolescents, programs should strengthen parent child communication. Strategies to educate parents on adolescents' sexuality issues with age specific messages should be developed. Programs should also focus on messages that encourage both female and male adolescent's communication on sexuality issues and use of contraceptives.

The study has shown that knowledge does not always equal practice therefore more research is needed to identify ways of converting knowledge into practice. The role of male partners in enhancing adolescence contraceptive uptake should also be investigated since they usually play initiative role in sex behaviour.

\section{Acknowledgements}

We would like to acknowledge the Department of Environmental Health, Kenyatta University for the materials to conduct this study. Our sincere gratitude goes to, Presbyterian University of East Africa, for supporting this research, the County Commissioner and the County Director of Education Kiambu County for granting us the permission to carry out the study in Kiambu County. We also appreciate the support granted by the secondary schools in Karuri Town Council during this study.

\section{References}

[1] WHO (2008) Why Is Giving Special Attention to Adolescents Important for Achieving Millenium Development Goal 5? The Millenium Development Goals Report 2011. New York, United Nations.

[2] WHO (2007) Unsafe Abortion: Global and Regional Estimates on the Incidence of Unsafe Abortion and Associated Mortality in 2003. WHO, Geneva.

[3] UNICEF (2012) Progress for Children: A Report Card for Adolescents. UNICEF, New York.

[4] WHO (2011) The Sexual and Reproductive Health of Younger Adolescents: Research Issues in Developing Countries. WHO, Geneva.

[5] UNFPA (2013) State of World Population 2013: Motherhood in Childhood; Facing the Challenges of Adolescent Pregnancy. Africa Exacts. UNFPA.

[6] Bankole, A. and Malarcher, S. (2010) Removing Barriers to Adolescents Access to Contraceptives Information and Services. Studies in FP, 41, 261-274.

[7] Oindo, M. (2002) Contraception and Sexuality among Youths in Kisumu Kenya. African Health Sciences, 2, 33-39.

[8] Blum, R. (2007) Youth in Sub-Saharan Africa. Journal of Adolescent Health, 41, 230-238. http://dx.doi.org/10.1016/j.jadohealth.2007.04.005

[9] Nyalali, K., Maternowska, C., Brown, H., Testa, A., Coulson, J. and Gordon-Maclean, C. (2013) Unintended Pregnancy among Teenagers in Arusha and Zanzibar, Tanzania. A Situation Analysis. Marie Stopes International. 
[10] International Planned Parenthood Federation (2007) Effective Strategies in Sexual and Reproductive Health. IPPF/WHR, New York.

[11] Jane, D. and Brown, C. (2005) Mass Media as a Sexual Super Peer for Early Maturing Girls. Journal of Adolescent Health, 36, 420-427. http://dx.doi.org/10.1016/j.jadohealth.2004.06.003

[12] Rose, N. (2012) Protecting In-School Adolescents from HIV/AIDS, STIs and Unwanted Pregnancy: Evidence-Based Lessons from Programs and Polic. African Population and Health Research Centre, Nairobi, Kenya.

[13] Khan, S. and Mishra, V. (2008) Youth Reproductive and Sexual Health. DHS Comparative Report No. 19. Macro International Inc., Calverton, Maryland, USA.

[14] Hussain, R. (2012) Abortion and Unintended Prgenancy in Kenya. Issues in Brief (Alan Guttnacher Institute), New York, No. 1.

[15] Sarrah, C.R. (2008) Effect of Pregnancy Intention on Child Well-Being and Development: Combining Retrospective Reports of Attitude and Contraceptive Use. Population Research and Policy Review, 24, 593-615.

[16] Chaaban, J. and Cunningham, W. (2011) Life Expectancy: Measuring the Economic Gain of Investing in Girls: The girl Effect Dividend. World Bank, Washington DC. http://dx.doi.org/10.1596/1813-9450-5753

[17] $\mathrm{MOH}$ (2007) A System in Crisis from Contraception to Post Abortion Care. Nairobi, Kenya.

[18] Apter, D. (2012) Adolescent Contraception: The Sexual Health Clinic. Family Federation of Finland. http://dx.doi.org/10.1159/000326704

[19] Tripp, J. and Russell, V. (2005) ABC of Sexual Health, Contraception and Teenage Pregnancy. British Medical Journal, 330, 590. http://dx.doi.org/10.1136/bmj.330.7491.590

[20] Godia, P., Olenja, J., LavussaL, J., Quinney, D., Hofman, J. and Broek, N. (2013) Sexual Reproductive Health Service Provision to Young People in Kenya; Health Service Providers' Experiences. BMC Health Service Research, 13, 476. http://dx.doi.org/10.1186/1472-6963-13-476

[21] Moore, K., Miller, B., Sugland, B., Morrison, D., Glei, D. and Blumenthal, C. (2008) Beginning too Soon: Adolescent Sexual Behavior, Pregnancy and Parenthood. A Review of Research and Interventions.

[22] Jay, S., Durant, R., Shoffitt, T., Linder, C. and Litt, I. (2007) Effects of Peer Counselors on Adolescent Compliance in Use of Oral Contraception. Paediatrics, 76, 126-131. http://www.ncbi.nlm.nih.gov/pubmed/6694867 
Submit or recommend next manuscript to SCIRP and we will provide best service for you:

Accepting pre-submission inquiries through Email, Facebook, LinkedIn, Twitter, etc. A wide selection of journals (inclusive of 9 subjects, more than 200 journals)

Providing 24-hour high-quality service

User-friendly online submission system

Fair and swift peer-review system

Efficient typesetting and proofreading procedure

Display of the result of downloads and visits, as well as the number of cited articles

Maximum dissemination of your research work

Submit your manuscript at: http://papersubmission.scirp.org/ 